\title{
3 Research Square

\section{Diabetics' self-care practice and its determinants among Adult diabetic patients in Ethiopia: A systematic review and meta-analysis.}

Fikadu Ambaw Yehualashet ( $\square$ fekaduambaw14@gmail.com )

University of Gondar College of Medicine and Health Sciences https://orcid.org/0000-0001-9204-6521

Wuber Worku Takele

University of Gondar, CMHSs

Eleni Tesfaye Tegegne

University of Rwanda College of Medicine and Health Sciences

Amare Demsie Ayele

University of Gondar College of Medicine and Health Sciences

Research article

Keywords: Diabetic self-care, Ethiopia, Systematic Review and Meta-analysis

Posted Date: December 13th, 2019

DOI: https://doi.org/10.21203/rs.2.18987/v1

License: (9) This work is licensed under a Creative Commons Attribution 4.0 International License.

Read Full License 


\section{Abstract}

Background: Appropriate diabetic self-care is indispensable to prevent and limit diabetic associated short and long term complications including death. Therefore, this comprehensive systematic review and metaanalysis were aimed at exploring and determining the pooled national percentage of diabetic self-care and its determinants among adult diabetic patients in Ethiopian.

Methods: Different electronic databases including PubMed/Medline and search engines such as Google scholar were used to retrieve published studies. The Joanna Briggs Institute (JBI) quality appraisal checklists were used to appraise the quality of studies. Data were extracted using excel spreadsheets and analyses were done by STATA 14 . Heterogeneity among studies was diagnosed using the I2. The DerSimonian and Laird random-effects model was employed for substantial heterogeneity (12>50\%). Sensitivity and subgroup analyses were carried out. The funnel plot and Egger's regression test was used to identify publication bias. Moreover, the nonparametric trim and fill analysis was done for findings with significant Egger's test $(p<0.05)$ and asymmetric distribution of studies in the funnel plot. The pooled estimate of diabetic self-care and odds ratio was reported based on the $95 \% \mathrm{Cl}$.

Results: Well over half of the Ethiopian diabetic patients have good self-care 54.04\% (47.07-61.01, 12 $=97.3, \mathrm{P}<0.001)$. Subgroup analysis showed that the highest and the lowest pooled estimate of self-care was detected in Southern Nations Nationalities and Peoples and Hareri region with $81.96 \%$ and $44.53 \%$ respectively. Being knowledgeable about diabetes mellitus $2.69 \%$, having good social support $2.25 \%$, owning private glucometer $3.04 \%$, and being urban residents $3.26 \%$ have promoted diabetic victims to apply self-care practice.

Conclusions: Despite the life-threatening complications of diabetes mellitus, the percentage of patients applying self-care has remained low in Ethiopia, depicting the high proportion of diabetic patients are prone to develop long and short term life-threatening consequences of diabetes mellitus. Therefore, improving the client's awareness about the disease and counseling clients about the significance of social support are believed to be possible strategies to improve self-care practice and policymakers are strongly recommended to combat diabetic associated complications to attain sustainable development goal 3.4 aims to reduce premature death.

\section{Introduction}

Diabetes mellitu $s$ is a chronic metabolic chaos of glucose homeostasis and linked with short and long term vascular and non vascular complications leading to illness and death. It is the rapid mounting noncommunicable disease all over the world(1). It is characterized by hyperglycemia that attributed to poor performance of anabolic hormone, insulin that compromises the body's ability to metabolize and uptake glucose to generate energy (2-4). The prevalence of diabetes has reached epidemic proportions; the World Health Organization (WHO) predicts that developing countries will bear the brunt of this epidemic by the 21 st century (5). Of the seven International Diabetes Federation (IDF) regions, the highest 
prevalence of DM was recorded in North America and the Caribbean (11.5\%), while Africa, fortunately, has shared the lowest burden (3.8\%). However, Africa is projected to share the largest burden by the year 2040 with $147 \%$ increment (3). Moreover, diabetes has affected the quality of life of the victims and led to poor health outcomes of individuals, families, and the broader communities. Consequently, it compromises the social and economic performance of nations (5-7).

Likewise, well over three-fourths (77\%) of morbidity and $88 \%$ of mortality have resulted from DM, which happened in low- and middle- income countries according to the 2012 report (6). DM curse is expected to affect nearly 592 million people globally by the end of 2035(6). In Ethiopia, the magnitude of diabetes was ranged from 3.5 and 4.36\% in the year 2011 and 2013, respectively. Likewise, in 2013, just over a quarter of million $(34,262)$ patients out of 1.8 million DM cases have died $(8)$. Even though DM exposes to lots of acute and chronic life-threatening complications, it's possible to limit these scourges through appropriate self-care practice. Self-care is the act of individualized, care with the intention of promoting health, preventing disease, and restoring health (9). DM requires a lifelong self-care behavior, which includes adherence to diet, performing physical activity, blood glucose monitoring, and good compliance to the treatment(10). Appropriate self-care practice is quite crucial to prevent diabetic associated complications, delay the occurrence of co-morbidities, and promote health outcomes of patients $(11,12)$. Poor self-care practice, however, rises the chance of experiencing complications including retinopathy, nephropathy, neuropathy, vision impairment, painful paresthesia, and psychiatric disorders (7). Although several studies have been conducted to estimate the burden and associated factor of diabetic self-care practice in different parts of Ethiopia, the national self-care estimate and factors were presented in arbitrarily. Hence, this systematic review and meta-analysis were aimed to estimate the pooled prevalence of diabetic self-care and its determinants among adult diabetic patients in Ethiopia. The findings of this review are believed to provide a piece of comprehensive evidence to clinicians, researchers, and programmers working on tackling DM and its associated aliments. In addition, the study will have a contribution to the attainment of Sustainable Development Goals (SDG) 3.4 that aimed at declining the magnitude of premature death following DM by a third.

\section{Methods}

\section{Protocol registration and review reporting}

Protocol registration is under-review in the prospective Register of Systematic Review and Meta-analysis (PROSPERO). The PRISMA checklist and the Meta-analysis Of Observational Studies in Epidemiology (MOOSE) was also used to present the methods and findings of the study $(13,14)$. All eligible primary articles were qualitatively described in terms of the prevalence, study setting, sample size, and other important characteristics. Screening and selection procedures of the eligible studies were illustrated through the PRISMA flow chart. Moreover, the results of the study were presented using tables, texts, and figures.

\section{Data source and search strategy}


Firstly, different websites and data sources were explored to check the availability of similar studies and to avoid duplications. Then, to gather published primary studies, databases such as PubMed/Medline, Scopus, and the Health Internetwork Access to Research Initiative (HINARI) were used, and extra articles and grey literature were also retrieved using electronics search engines of Google and Google scholar. Also, the reference lists of the relevant articles were tracked to access extra studies. To suppress the number of irrelevant articles during the searching process, the searching was limited to "human studies", published in English language and studies conducted since 2010G.C. The search strategy has been built using keywords that have been identified using the "Medical Subject Headings (MeSH)" terms and "All fields" by linking "AND "and "OR" Boolean operator terms as appropriate, yielding a search strategy of (Diabet*) OR Diabet*[MeSH Terms] AND self care OR self-care OR self-care management OR management AND practi* ${ }^{A N D}$ determin* OR associat* OR predict* AND Ethiopia.

All the searching process was completed after four months on September, 2019.

\section{Outcome}

Diabetes self-care: Diabetic self-care includes self-monitoring of blood glucose (SMBG), adequate nutrition, physical activity (PA), Foot care (FC), and compliance with medication $(2,9,15)$. It was mentioned more than ten times among included studies.

\section{Eligibility criteria of studies}

\section{Inclusion criteria}

- Cross-sectional and analytical cross-sectional

- Studies conducted in Ethiopia since 2010G.C and written in English

\section{Exclusion Criteria:}

- Studies conducted among children aged less than 18 years.

- Studies done before 2010.

- Qualitative studies and Case control studies

\section{Risk of bias and quality assessment}

The quality of the selected studies has been assessed by three reviewers (FAY, ADA, and WWT). The Joanna Briggs Institute (JBI) critical appraisal tool for cross-sectional for the prevalence studies (16) and analytic cross-sectional studies (17) for the factors were used for the appraisal. The tool has 'Yes' and 'No' question type, and ' 1 ' and ' 0 ' values were given, respectively; then the numbers were converted to percentage after summing the results. Articles that scored greater than or equal to $50 \%$ were included in the systematic review as well as meta-analysis. Disagreements between the assessors were managed after inviting an extra evaluator (ETT). 


\section{Data collection process}

After eligible studies have been selected, two authors (FAY and ADA) extracted the relevant data using Microsoft Excel spreadsheets. The following variables were extracted from each article: name of the first author, year of study, study area, sample size, response rate, proportion, and pertinent associated factors. For prevalence studies, the prevalence, the logarithm of the prevalence, and the standard error of logarithm of the prevalence were calculated. In addition, to compute the determinant factors, the odds ratio, logarithms of the odds ratio, and the standard error of the logarithms of odds ratio were calculated.

\section{Data analysis and assessment of publication bias:}

The extracted data were exported to STATA/SE version 14 (STATA Corporation, College Station, Texas, USA) for further analysis. Heterogeneity between studies was assessed subjectively through observing the forest plots and objectively by checking the Cochrane Q statistics and $I^{2}$ heterogeneity test (18). The $\mathrm{I}^{2}$ values of $25 \%, 50 \%$, and $75 \%$ were labeled as the presence of the low, medium, and high heterogeneity, respectively. $I^{2}$ heterogeneity test of $\geq 50 \%$ with its corresponding p-value $<0.05$ was considered as the existence of heterogeneity. Thus, the DerSimonian Laird random-effects model was applied (19). Sensitivity analysis was carried out to explore the source of variation among studies using a command 'metaninf' (20). Subgroup analyses were done by regions and study year. Furthermore, publication bias was explored using funnel plots (21) and statistically, through Egger's regression test (22). Accordingly, symmetrical alignment of studies over the funnel plot and/or statistical significance of Egger's regression test ( $p$-value $\geq 0.05$ ) was used to declare the absence of publication bias. Therefore, in order to consider the suppressed studies during the publication process, using "metatrim" command, a nonparametric trim and fill (Duval and Tweedie's) method of analysis was done (23). All statistical reports were done with its $95 \% \mathrm{Cl}$. Interpretations were made based on the pooled odds ratio and $p$-value $\leq 0.05$ and excluding the null value (1) in the confidence interval were considered as there was the presence of an association between diabetic self-care and its covariates.

\section{Results}

\section{Study screening and selection processes}

A total of 3861 studies have been identified through the searching strategy from different databases, of which four of them were from University repository and unpublished articles. One hundred fifty studies remained after removing the duplications. Finally, nineteen studies left eligible and included in the study (Figure 1).

\section{Characteristics of included primary studies}

A total of nineteen studies yielding a total study population of 6595 was eligible and included for both qualitative and quantitative analyses. Amhara, Oromia, and Hareri 
regions contributed $26.3 \%(24-28), 21 \%(6,11,29,30)$, and $157 \%(2,7,31)$ to the total of included studies, respectively. Three regions: Southern Nations Nationalities and Peoples (SNNPs) $(10,32)$, Tigray $(33,34)$, and Addis Abeba $(8,35)$ each contributed two articles to the review. While the remaining study was from Benishangul Gumuz region(36). Significant variation was observed with the sample size of the included studies; the highest sample size was 660 from a study conducted in Addis Abeba (8) and the least was 191 from a study done in SNNPs(32). Referring to the response rate, the lowest and the highest response rates were 95\% and 100\% consecutively. Furthermore, the prevalence of diabetics self-care practice falls between $28.4 \%$ and $76.8 \%$ from a study conducted in Amhara (27) and SNNPs(10) regions, respectively. All the studies incorporated were simple and analytical cross-section by design (Table 1).

Table1. General characteristics of included studies that report the prevalence of diabetic's self-care practice, 2019. 


\begin{tabular}{|c|c|c|c|c|c|c|}
\hline Authors Name & $\begin{array}{l}\text { study } \\
\text { year }\end{array}$ & Region & $\begin{array}{l}\text { Sample } \\
\text { size }\end{array}$ & $\begin{array}{l}\text { Response } \\
\text { rate }\end{array}$ & Prevalence & $\begin{array}{l}\text { Quality } \\
\text { (JBI Score) }\end{array}$ \\
\hline $\begin{array}{ll}\text { Addisu } & Y \\
\text { et.al(10) } & \end{array}$ & 2013 & SNNPE & 310 & 100 & 76.8 & $75 \%$ \\
\hline Dedefo et al(29) & 2016 & Oromia & 252 & 100 & 60.7 & $75 \%$ \\
\hline $\begin{array}{l}\text { Feyissa } \\
\text { et.al(35) }\end{array}$ & 2014 & AddisAbeba & 328 & 98.8 & 51.5 & $62 \%$ \\
\hline $\begin{array}{ll}\text { Fikadu } & \text { A } \\
\text { et.al(24) } & \end{array}$ & 2017 & Amhara & 344 & 100 & 50 & $75 \%$ \\
\hline Getie et.al(7) & 2018 & DireDawa & 513 & 98.6 & 55.9 & 100 \\
\hline $\begin{array}{lll}\text { Gurmu } & Y & \text { et } \\
\operatorname{al}(11) & & \end{array}$ & 2017 & Oromia & 257 & 100 & 54.5 & $75 \%$ \\
\hline $\begin{array}{l}\text { Haftom } \\
\text { et.al(33) }\end{array}$ & 2016 & Tigray & 338 & 100 & 74.5 & $75 \%$ \\
\hline $\begin{array}{ll}\text { Kassahun } & \mathrm{T} \\
\text { et.al(6) } & \end{array}$ & 2014 & Oromia & 309 & 95 & 50.9 & $62 \%$ \\
\hline $\begin{array}{l}\text { Ketema } \\
\text { et.al(31) }\end{array}$ & 2011 & Harer & 222 & 100 & 39.2 & $50 \%$ \\
\hline Melat et.al(8) & 2011 & AddisAbeba & 660 & 97.8 & 60.3 & $62 \%$ \\
\hline Mende et.al(32) & 2015 & SNNPE & 194 & 100 & 87.1 & $75 \%$ \\
\hline Segni et.al(36) & 2018 & B.Gumuz & 383 & 96 & 54.3 & $62 \%$ \\
\hline $\begin{array}{l}\text { Sofonyas } \quad \text { A } \\
\text { et.al(25) }\end{array}$ & 2018 & Amhara & 385 & 95 & 63.1 & $62 \%$ \\
\hline $\begin{array}{l}\text { Solomon A et } \\
\text { al(26) }\end{array}$ & 2012 & Amhara & 410 & 97.2 & 36.8 & $62 \%$ \\
\hline Tadele et.al(30) & 2013 & Oromia & 260 & 98 & 55 & $62 \%$ \\
\hline $\begin{array}{l}\text { Teklewoini } \\
\text { et.al(34) }\end{array}$ & 2017 & Tigray & 284 & 100 & 37.3 & $62 \%$ \\
\hline Teshager & 2017 & Amhara & 416 & 99.5 & 28.4 & $75 \%$ \\
\hline
\end{tabular}




\begin{tabular}{|l|l|l|l|l|l|l|} 
etal(27) & & & & & & \\
\hline $\begin{array}{l}\text { Behailu } \\
\text { et.al(2) }\end{array}$ & 2017 & Harer & 327 & 97.8 & 38.1 & $75 \%$ \\
\hline Andualem et.al & 2019 & Amhara & 403 & 100 & 51.86 & $75 \%$ \\
\hline
\end{tabular}

In the random-effects model, diabetic self-care practice was $54.04 \%\left(47.07-61 \%, \mathrm{I}^{2}=97.3 \%\right.$, $\mathrm{P}<0.001$ ) (Figure 2.).

\section{Sensitivity analysis}

There was no influential study that caused variation between studies, according to the sensitivity analysis.

The subgroup analysis by the regions where studies were conducted suggested that notable difference among regions has been observed; the lowest (45.33\%) and highest (81.93\%) prevalence was recorded in Amhara and SNNPs regions, respectively. For the sake of analysis, one study from Benishangul Gumuz region was included into Amhara region based on physical proximity as well as the proportion of study population in the area (Figure3).

The absence of influential study has revealed through sensitivity analysis, and the presence of publication bias has ruled out by the funnel plot (Figure 4.) and Egger's regression test $(\mathrm{P}$ value $=0.568)$.

\section{Determinants of diabetics' self-care practice}

Five published articles were included to explore and determine the association between diabetic's knowledge and self-care practice. Of the included studies, studies from Diredawa (7), Oromia (11), Addis Ababa (8), and Amhara (25) regions have shown a significant association; patients who had good knowledge about diabetics were good at applying selfcare practice. However, a study conducted in the Tigray region did not show an association (34). 
The meta-analysis result revealed that having diabetic knowledge was about 2.7 times more likely to perform self-care than their counterparts $\left.2.69(1.62,4.46), \mathrm{I}^{2}=99 \%, \mathrm{P}<0.001\right)$ (Figure 4).

No influential study according to the sensitivity analysis. Publication bias was not seen as to the egger's test demonstrated $(p=0.892)$.

The effect of social support on diabetic self-care practice has been explored among six studies $(7,8,11,25,29,36)$. Of these, five of the studies revealed that good social support promotes self-care practice. The odds of performing self-care among diabetic victims having good social support were increased two folds $2.25\left((1.49-3.39) ; \mathrm{I}^{2}=99 \%, \mathrm{p}=0.00\right)$ as compared to those who had no good social support (Figure 6).

There was no influential study that resulted in variation among studies and publication bias was not seen $(p=0.752)$.

Further to the aforementioned factors, the relationship between having glucometer at home and diabetic's self-care practice has been explored, and six studies $(6,7,25,29,34,36)$ were involved in to the analysis; all the included studies were significantly associated with self-care practice. in other words, DM patients who have glucometer at home were three times more likely to practice diabetics self-care compared to patients who didn't have access to glucometer at home 3.04(1.64, 5.65; $\mathrm{I}^{2}=97.4, \mathrm{P}<=0.001$ )(Figure 7). The sensitivity analysis depicted no study that accounted for the variation. The funnel plot illustrates symmetric distribution of studies and Egger's regression supports the finding ( $\mathrm{P}$ $=0.631)$.

Four primary studies $(29,34-36)$ were screened and included to examine the relationship between co-morbidities and diabetics self-care practice. A significant association was observed among five studies (7, 25, 29, 34, 36), However, a study showed a protective association (6). As a result, the pooled effect size of the presence of co-morbidity showed an absence of significant association with diabetics self-care practice $1.24(0.8,1.91) ; \mathrm{I}^{2}=97.8$, 
$\mathrm{p}<=0.001$ ) (Figure 8). No influential study and publication bias $(\mathrm{p}=0.904$ ) has been detected.

Furthermore, the relationship between diabetic's self-care practice and residence of DM patients was reviewed by five articles. All studies (25, 28, 29, 33, 36) demonstrate that being an urban residence promoted diabetic self-care practice. The effect size of the residence revealed that living in an urban area has a threefold chance of practicing diabetics self-care than DM patients residing in the rural area $3.26(2.24,4.74), \mathrm{I}^{2}=96.3 \%$, $\mathrm{P}<0.001$ ) (Figure9). The analysis result indicated that there is no small study that affects the pooled estimate and the absence of publication bias $(P=0.296)$.

\section{Discussion}

Diabetes is one of the major global health problems that require continuous self-care practices to prevent potential acute and long-term complications (11). Self-care practice is a cornerstone of diabetes management that can ensure the involvement of clients to promote their health and prevent further short and long term complications. Studies revealed that almost all of the diabetes management depends on good self-care behaviors and DM clients stick on self-care practice can avert development the occurrence of diabetes-associated illnesses DM (25).

The finding of this study indicated that the pooled national prevalence of good self-care practice among DM patients in Ethiopia is 54.04\% (47.07-61.01) which designates a significant number of DM patients have poor self-care practice. As a result, their chance of developing short and long term DM complication becomes higher. Morbidity and death related to DM might be increasing, as poor diabetic's self-care practice is strongly correlated with its adverse health outcomes.

According to the regional subgroup analysis, the highest pooled estimate (81.93\%) was from studies conducted in SNNPs and the lowest estimate (45.33\%) was from Hareri region. This variation might be due to the socio-demographic differences of the study population; as more than $85 \%$ of the participants of studies conducted in SNNPs can read and write, while about one-third of participants from the studies in Harer can't read and write. Education significantly affect adherence of patients to the recommended diabetics self care diabetics self-care practice.

Diabetics related knowledge, having social support, having own glucometer at home and residence were found independent predictors of diabetics self-care practice in Ethiopia. Having good knowledge about diabetes has increased the self-care practice by two-fold compared to participants with poor knowledge; this evidence is supported by a study conducted in lower and middle income countries/LMIC that states; extensive knowledge on diabetes and attitude towards self-care could be the means to control and prevent diabetes related complications(37). Furthermore, this finding is supported by another studies, as 
poor diabetics knowledge could result in low literacy levels or poor understanding about the disease process and its complications, which could arise from lack of education by health professionals (38). Hence, it could be important to take a note that educating DM patient to increase their level of knowledge about the disease condition and associated potential complications and would enhance self-care practice and limit life-threatening complications as a result of the disease.

The current study has been evidenced that good social support improves good self-care practice; the same finding revealed in the United States (US) [42]. The inspiration of DM patients to self-care practice is seen to be improved by self-confidence, the presence of family support, and positive changes in relationships; besides, having better social support contribute to individual self-efficacy, which has a crucial role on self-care behaviors, that leading to increased self-care activities and bring better health outcomes (39). In addition, social interaction and support could enhance the self-esteem and promotes self-caring ability of DM patients(40); interaction with other individuals could allow them to explain the problems that they are experiencing and possible measures and ideas could be raised and shared and, good social support could promote different dimensions of health such as mental, social and emotional health, as a result, victims may take care of themselves and practice anything that could bring wellness. Therefore, promoting social support through establishing different mechanisms for instance, through health extension workers, and strengthening neighborhood could be crucial measures to promote selfcare and prevent life-threatening complications as a result(41).

Based on the finding of this meta-analysis, having a personal glucometer is found to be an important determinant factor affecting diabetic's self-care practice. Those DM patients who have their own glucometer have three fold chance of practicing self-care compared to their counterparts. This finding is supported by a study conducted in Pakistan (42).

Furthermore, residence of DM patients is another predictor of diabetic's self-care practice. Those DM patients residing in the cities/urban area have three times more likely to practice self-care compared to the rural dwellers. Urban resident DM patients have better access of diabetics' education through different Medias which provide them an opportunity to manage their diabetics and prevent complications. In addition, urban residents are advantageous to access of the health facilities, treatment options, and glucose monitoring devices. Clinicians should give due emphasis to educate rural residents on basic components of diabetics self-care practice.

\section{Conclusion And Recommendation}

The magnitude of good self-care practice in Ethiopia is low. Noticeable variation among regions has been identified with the highest and lowest proportion of self care practice recorded in SNNPs and Hareri regions respectively. Having better Diabetics knowledge, good social support, having private glucometer, and being an urban dweller have improved diabetic's self-care practice. Clinicians are advised to work on diabetic's education in order to increase the awareness and skill required to perform Diabetics self- care practice. It is advisable to promoting social support through family partnership interventions and 
involving family in the management of diabetes patients. On top of this, the Federal ministry of health, regional and local organizations as well as DM associations are encouraged to work collaboratively to increase availability and accessibility of glucometer test kits. Special emphasis has to be provided to rural resident DM patients by the government and other stakeholders to improve their level of diabetic's knowledge, attitude and their self care practice through health education and improving quality of health care.

\section{Strength of the study}

As far as our search this article is the first systematic review and meta analysis conducted on diabetics self care practice. Conducted following exhaustive long time searching on different data sources; and, has been presented by the standardized systematic review and meta-analysis checklist; PRISMA, for its scientific rigorous.

\section{Limitations of the study:}

Despite the aforementioned strong sides, the study has its own drawbacks to be considered. One of the limitations is related to searching accuracy; some studies may be overlooked and non accessible in the data bases identified. The other constraint is the exclusion of qualitative studies from the review. On top of this, case control studies were also excluded due to its problem related to ascertainment of the outcome.

\section{Declarations}

\section{- Abbreviations:}

\begin{tabular}{ll} 
DM & Diabetics mellitus \\
\hline JBI & Joanna Briggs Institute \\
\hline DCCT & Diabetes Control and Complication Trial \\
\hline LMICs & lower and middle income countries \\
\hline IDF & International Diabetes Federation \\
\hline PROSPERO & prospective register of Systematic Review and meta-analysis \\
\hline PRISMA & Preferred Reporting Items for Systematic Reviews and Meta-Analyses \\
\hline MOOSE & Meta-analysis Of Observational Studies in Epidemiology \\
\hline SNNPs & Southern Nations Nationalities and Peoples
\end{tabular}

- Ethics approval and consent to participate: Not applicable

- Consent for publication: Not applicable 
- Availability of Data and material: All data are included in the paper, the corresponding author will provide upon the request, however.

- Competing interests: The authors have declared that there is no any competing interest

- Funding: Not any funding received for this work

- Authors' Contributions

Fikadu Ambaw Yehualashet was responsible for conceptualization, project administration, software, supervision, and original drafting of the manuscript.

Fikadu Ambaw Yehualashet, Eleni Tesfaye Tsegaye, Wubet Worku Takele and Amare Demissie Ayele have participated in quality assessment of articles, methodology, validation, and screening of research papers. All authors have contributed with data analysis, critically revised of the paper, and agreed to be accountable for their individual contributions.

\section{- Acknowledgments}

We would like to thank all the primary authors of included articles and the participants of each primary studies.

\section{References}

1. Imam K. Clinical features, diagnostic criteria and pathogenesis of diabetes mellitus. Diabetes: Springer; 2013. p. 340-55.

2. Ayele BH, Mengesha MM, Tesfa T. Predictors of self-care activities of outpatient diabetic residents in Harar and Dire Dawa: A hospital-based cross-sectional study. SAGE open medicine. 2019;7:2050312119865646.

3. Fasil A, Biadgo B, Abebe M. Glycemic control and diabetes complications among diabetes mellitus patients attending at University of Gondar Hospital, Northwest Ethiopia. Diabetes, metabolic syndrome and obesity : targets and therapy. 2019;12:75-83.

4. Berhe K, Gebru H, Kahsay H, Kahsay A. Assessment of Diabetes Knowledge and its Associated Factors among Type 2 Diabetic Patients in Mekelle and Ayder Referral Hospitals, Ethiopia. J Diabetes Metab 5: 378. doi: 10.4172/2155-6156.1000378 Page 2 of 7 J Diabetes Metab ISSN: 2155-6156 JDM, an open access journal Volume 5• Issue 5• 1000378. study participants. 2014;171(57):3.

5. Angamo MT, Melese BH, Ayen WY. Determinants of glycemic control among insulin treated diabetic patients in Southwest Ethiopia: hospital based cross sectional study. PLoS One. 2013;8(4):e61759.

6. Kassahun T, Gesesew H, Mwanri L, Eshetie T. Diabetes related knowledge, self-care behaviours and adherence to medications among diabetic patients in Southwest Ethiopia: a cross-sectional survey. BMC endocrine disorders. 2016;16(1):28.

7. Getie Mihret A, Alemayhu T, Geda B. Self-Care Practices and Associated Factors among Adult Diabetic Patients in Public Hospitals of Dire Dawa Administration, Eastern Ethiopia: Haramaya 
University; 2018.

8. Mamo M, Demissie M. Self care practice and its associated factors among diabetic patients in addisababa public hospitals, cross sectional study. J Diabetes Cholest Metabol. 2016;1(1):2-5.

9. Schoenberg NE, Traywick LS, Jacobs-Lawson J, Kart CS. Diabetes self-care among a multiethnic sample of older adults. Journal of cross-cultural gerontology. 2008;23(4):361-76.

10. Addisu Y, Eshete A, Hailu E. Assessment of diabetic patient perception on diabetic disease and selfcare practice in Dilla University Referral Hospital, South Ethiopia. J Metabolic Synd. 2014;3(166):2167-0943.1000166.

11. Gurmu Y, Gela D, Aga F. Factors associated with self-care practice among adult diabetes patients in West Shoa Zone, Oromia Regional State, Ethiopia. BMC health services research. 2018;18(1):732.

12. Hailu E, Mariam WH, Belachew T, Birhanu Z. Self-care practice and glycaemic control amongst adults with diabetes at the Jimma University Specialized Hospital in south-west Ethiopia: A cross-sectional study. African journal of primary health care \& family medicine. 2012;4(1).

13. Moher D LA, Tetzlaff J, Altman DG, e1000097. . Preferred Reporting Items for Systematic Reviews and Meta-Analyses:.

14. Stroup DF, Berlin JA, Morton SC, Olkin I, Williamson GD, Rennie D, et al. Meta-analysis of observational studies in epidemiology: a proposal for reporting. Jama. 2000;283(15):2008-12.

15. Strom JL, Lynch CP, Egede LE. Rural/urban variations in diabetes self-care and quality of care in a national sample of US adults with diabetes. The Diabetes Educator. 2011;37(2):254-62.

16. Munn Z, Moola S, Lisy K, Riitano D, Tufanaru C. Methodological guidance for systematic reviews of observational epidemiological studies reporting prevalence and cumulative incidence data. International journal of evidence-based healthcare. 2015;13(3):147-53.

17. Mu oola S MZ, Tufanaru C, Aromataris E, Sears K, Sfetcu R, Currie M, Qureshi R, Mattis P, Lisy K, MPF. Chapter 7: Systematic reviews of etiology and risk . In: Aromataris E, Munn Z (Editors). .

18. Higgins JP, Thompson SG. Quantifying heterogeneity in a meta-analysis. Statistics in medicine. 2002;21(11):1539-58.

19. DerSimonian R, Laird N. Meta-analysis in clinical trials. Controlled clinical trials. 1986;7(3):177-88.

20. Cooper H, Hedges LV, Valentine JC. The handbook of research synthesis and meta-analysis: Russell Sage Foundation; 2009.

21. Sterne JA, Egger M. Funnel plots for detecting bias in meta-analysis: guidelines on choice of axis. Journal of clinical epidemiology. 2001;54(10):1046-55.

22. Sterne JA, Egger M, Smith GD. Systematic reviews in health care: Investigating and dealing with publication and other biases in meta-analysis. BMJ: British Medical Journal. 2001;323(7304):101.

23. Duval S, Tweedie R. A nonparametric "trim and fill" method of accounting for publication bias in meta-analysis. Journal of the American Statistical Association. 2000;95(449):89-98.

24. Yehualashet FAaAAD. Self-care practice and associated factors among diabetic patients at University of Gondar comprehensive Specialize referral hospital North West Ethiopia, 2017. . 2017. 
25. Tiruneh SA, Ayele AA, Emiru YK, Tegegn HG, Ayele BA, Engidaw MT, et al. Factors influencing diabetes self-care practice among type 2 diabetes patients attending diabetic care follow up at an Ethiopian General Hospital, 2018. Journal of diabetes and metabolic disorders. 2019;18(1):199-206.

26. Feleke SA, Alemayehu CM, Adane HT, Onigbinde A, Akindoyi O, Faremi F. Assessment of the level and associated factors with knowledge and practice of diabetes mellitus among diabetic patients attending at FelegeHiwot hospital, Northwest Ethiopia. Clin Med Res. 2013;2(6):110.

27. Abate TW, Tareke M, Tirfie M. Self-care practices and associated factors among diabetes patients attending the outpatient department in Bahir Dar, Northwest Ethiopia. BMC research notes. 2018;11(1):800.

28. Aschalew AY, Yitayal M, Minyihun A, Bisetegn TA. Self-care practice and associated factors among patients with diabetes mellitus on follow up at University of Gondar Referral Hospital, Gondar, Northwest Ethiopia. BMC research notes. 2019;12(1):591.

29. Dedefo MG, Ejeta BM, Wakjira GB, Mekonen GF, Labata BG. Self-care practices regarding diabetes among diabetic patients in West Ethiopia. BMC research notes. 2019;12(1):212.

30. Amente T, Belachew T, Hailu E, Berhanu N. Self care practice and its predictors among adults with diabetes mellitus on follow up at Nekemte hospital diabetic clinic, West Ethiopia. World J Med Med Sci [Internet]. 2014;2(3):1-16.

31. Ayele K, Tesfa B, Abebe L, Tilahun T, Girma E. Self care behavior among patients with diabetes in Harari, Eastern Ethiopia: the health belief model perspective. PLoS One. 2012;7(4):e35515.

32. Sorato MM, Tesfahun C, Lamessa D. Levels and predictors of adherence to self-care behaviour among adult type 2 diabetics at Arba Minch general hospital, Southern Ethiopia. J Diabetes Metab. 2016;7(6):11.

33. Niguse H, Belay G, Fisseha G, Desale T, Gebremedhn G. Self-care related knowledge, attitude, practice and associated factors among patients with diabetes in Ayder Comprehensive Specialized Hospital, North Ethiopia. BMC research notes. 2019;12(1):34.

34. Mariye T, Tasew H, Teklay G, Gerensea H, Daba W. Magnitude of diabetes self-care practice and associated factors among type two adult diabetic patients following at public Hospitals in central zone, Tigray Region, Ethiopia, 2017. BMC research notes. 2018;11(1):380.

35. LEMESSA F. ASSESSMENT OF SELF CARE PRACTICES AND ASSOCIATED FACTORS AMONG TYPE 2 DIABETIC PATIENTS AT TIKUR ANBESSA SPECIALIZED HOSPITAL ADDIS ABABA, ETHIOPIA. Addis Abeba University Library. 2014.

36. Chali SW, Salih MH, Abate AT. Self-care practice and associated factors among Diabetes Mellitus patients on follow up in Benishangul Gumuz Regional State Public Hospitals, Western Ethiopia: a cross-sectional study. BMC research notes. 2018;11(1):833.

37. Gautam A, Bhatta DN, Aryal UR. Diabetes related health knowledge, attitude and practice among diabetic patients in Nepal. BMC endocrine disorders. 2015;15(1):25.

38. Iregbu S, Iregbu F. A review of self-management of diabetes in Africa. African Journal of Diabetes Medicine Vol. 2016;24(2). 
39. Tan CCL, Cheng KKF, Sum CF, Shew JSH, Holydard E, Wenru W. Perceptions of diabetes self-care management among older Singaporeans with type 2 diabetes: A qualitative study. Journal of Nursing Research. 2018;26(4):242-9.

40. Ishak NH, Yusoff SSM, Rahman RA, Kadir AA. Diabetes self-care and its associated factors among elderly diabetes in primary care. Journal of Taibah University medical sciences. 2017;12(6):504-11.

41. Khymdeit E, Rao PA, Narayanan P, Mayya S. Social support influencing diabetes self-management behaviors: A cross-sectional study in Udupi Taluk. Indian Journal of Health Sciences and Biomedical Research (KLEU). 2016;9(2):153.

42. Ahmed MU, Seriwala HM, Danish SH, Khan AM, Hussain M, Husain M, et al. Knowledge, Attitude, and Self Care Practices Amongsts Patients WithType 2 Diabetes in Pakistan. Global journal of health science. 2016;8(7):1.

\section{Figures}

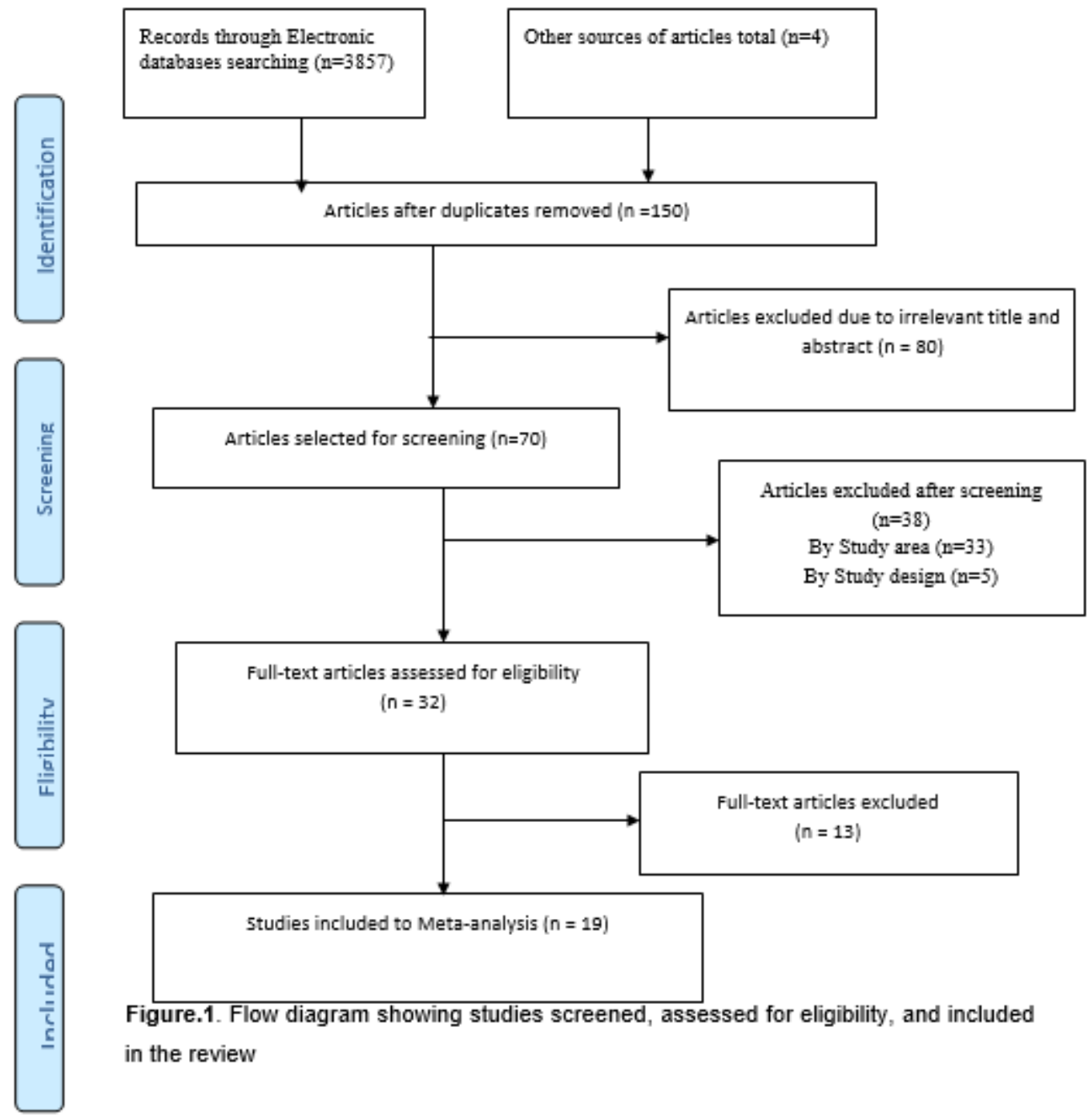

Figure 1 
Flow diagram showing studies screened, assessed for eligibility, and included in the review

\begin{tabular}{|c|c|c|c|c|}
\hline Study & & & & $\%$ \\
\hline ID & & & $\mathrm{ES}(95 \% \mathrm{Cl})$ & Weight \\
\hline Addisu $Y$ et.al (2013) & 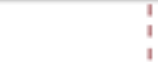 & $\leftarrow$ & $76.80(72.10,81.50)$ & 5.29 \\
\hline Dedefo et al (2016) & & & $60.70(54.67,66.73)$ & 5.21 \\
\hline Feyissa et.al (2014) & $\rightarrow$ & & $51.50(46.09,56.91)$ & 5.25 \\
\hline Fikadu $\mathrm{A}$ et al (2017) & $\rightarrow$ & & $50.00(44.72,55.28)$ & 5.26 \\
\hline Getie et. al (2018) & & & $55.90(51.60,60.20)$ & 5.31 \\
\hline Gurmu $Y$ et al (2017) & & & $54.50(48.41,60.59)$ & 5.21 \\
\hline Haftom et.al (2016) & 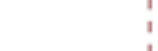 & $\leftarrow$ & $74.50(69.85,79.15)$ & 5.29 \\
\hline Kassahun T et.al (2014) & $\rightarrow$ & & $50.90(45.33,56.47)$ & 5.24 \\
\hline Ketema et.al (2011) & $\rightarrow \quad$ & & $39.20(32.78,45.62)$ & 5.18 \\
\hline Melat et.al (2011) & & & $60.30(56.57,64.03)$ & 5.34 \\
\hline Mende et.al (2015) & ' & 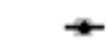 & $87.10(82.38,91.82)$ & 5.29 \\
\hline Segni et.al (2018) & & & $54.30(49.31,59.29)$ & 5.27 \\
\hline Sofonyas A et.al (2018) & & & $63.10(58.28,67.92)$ & 5.28 \\
\hline Solomon A et al (2012) & $\leftarrow$ & & $36.80(32.13,41.47)$ & 5.29 \\
\hline Tadele et.al (2013) & & & $55.00(48.95,61.05)$ & 5.21 \\
\hline Teklewoini et.al (2017) & $\rightarrow$ & & $37.30(31.68,42.92)$ & 5.24 \\
\hline Teshager etal (2017) & $\leftarrow$ & & $28.40(24.07,32.73)$ & 5.31 \\
\hline Behailu H et.al (2017) & $\rightarrow$ & & $38.10(32.84,43.36)$ & 5.26 \\
\hline andualem et.al (2019) & $\rightarrow$ & & $51.86(46.98,56.74)$ & 5.28 \\
\hline Overall $(1-$ squared $=97.3 \%, p=0.000)$ & & & $54.04(47.07,61.01)$ & 100.00 \\
\hline NOTE: Weights are from random effects analysis & i & & & \\
\hline & 1 & $T$ & & \\
\hline & 25 & 75 & & \\
\hline
\end{tabular}

\section{Figure 2}

Forest plot of the pooled prevalence of diabetic's self-care practice using the random-effects model, a systematic review and eta-analysis, Ethiopia, 2019. 


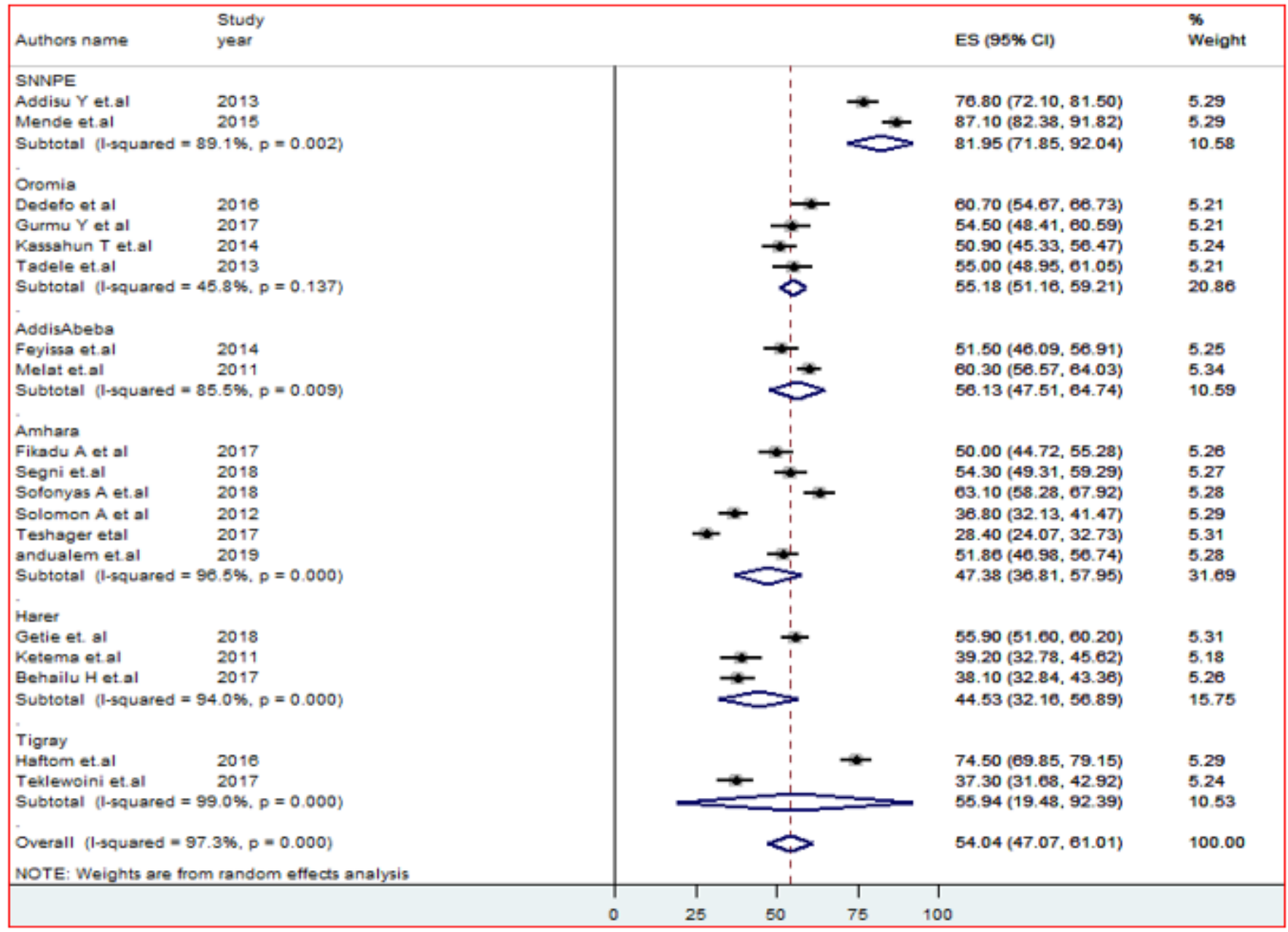

\section{Figure 3}

Forest plot showing subgroup analysis of prevalence of diabetics' self-care among Ethiopian DM patients by regions a systematic review and meta-analysis, Ethiopia, 2019. 


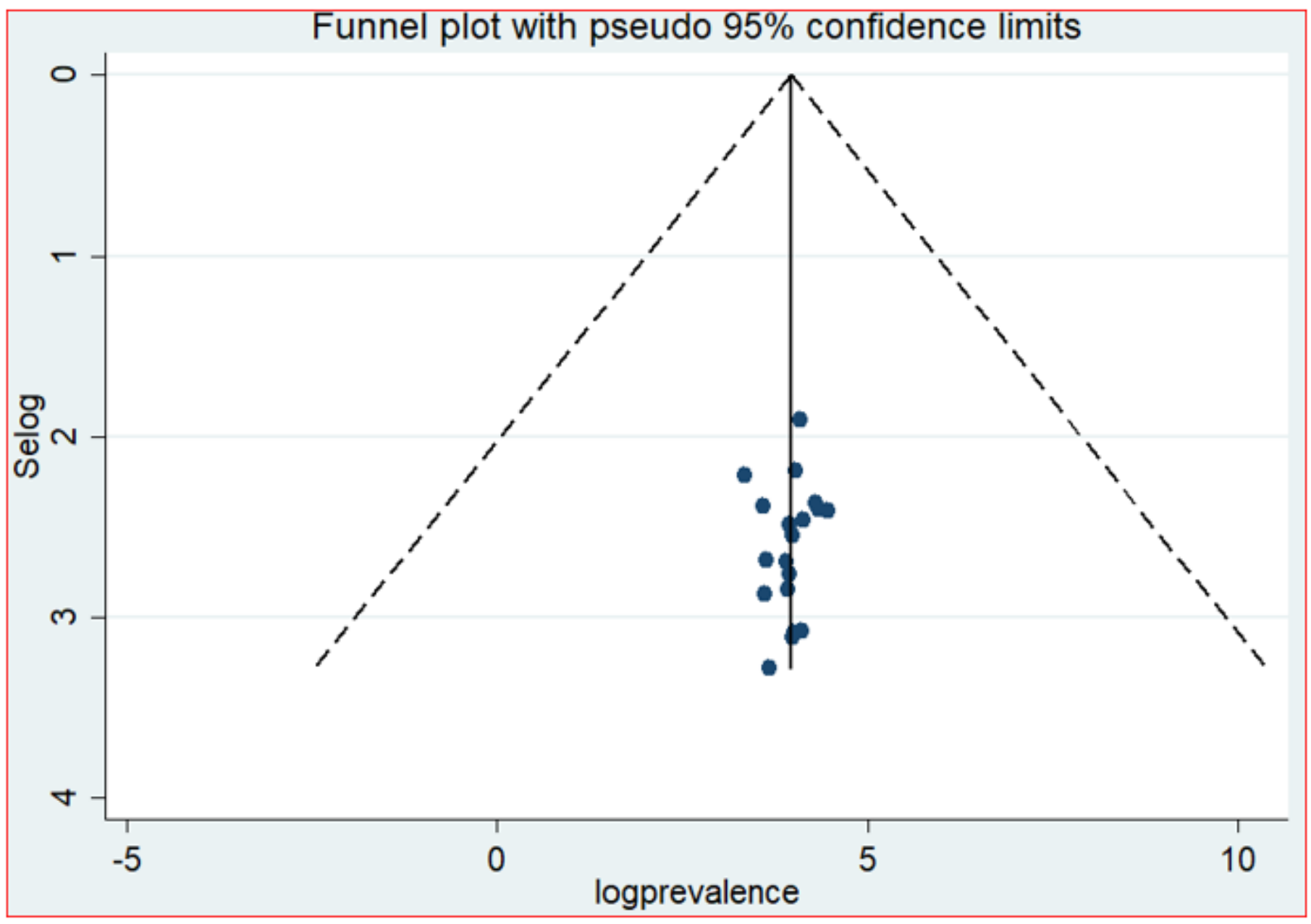

Figure 4

Funnel plot showing presence of publication bias among studies included a systematic review and meta analysis in Ethiopia, 2019. 


\begin{tabular}{|c|c|c|c|}
\hline Study & & & $\%$ \\
\hline ID & & ES $(95 \% \mathrm{Cl})$ & Weight \\
\hline Getie et. al (2018) & $\rightarrow$ & $3.34(3.12,3.58)$ & 20.21 \\
\hline Gurmu et al (2017) & $\rightarrow$ & $4.04(3.52,4.65)$ & 19.99 \\
\hline Melat et.al (2011) & $\longrightarrow$ & $4.96(4.05,6.08)$ & 19.64 \\
\hline Teklewoini et.al (2017) & & $1.00(0.89,1.13)$ & 20.06 \\
\hline Sofonyas A et.al (2018) & & $2.12(1.90,2.37)$ & 20.09 \\
\hline Overall $(\mathrm{l}$-squared $=99.0 \%, \mathrm{p}=0.000)$ & & $2.69(1.62,4.46)$ & 100.00 \\
\hline NOTE: Weights are from random effects analysis & & & \\
\hline 1 & & & \\
\hline
\end{tabular}

\section{Figure 5}

Forest plot showing the association between participants Knowledge about DM on self-care practice with 95\% Cls among DM patients in Ethiopia, 2019.

\begin{tabular}{|c|c|c|c|}
\hline \multirow{2}{*}{$\begin{array}{l}\text { Study } \\
\text { ID }\end{array}$} & & \multirow[b]{2}{*}{ ES $(95 \% \mathrm{Cl})$} & \multirow{2}{*}{$\begin{array}{l}\% \\
\text { Weight }\end{array}$} \\
\hline & & & \\
\hline Dedefo et al (2016) & & $0.60(0.51,0.71)$ & 16.43 \\
\hline Getie et. al (2018) & $\rightarrow$ & $3.51(3.17,3.87)$ & 16.73 \\
\hline Gurmu et al (2017) & $\rightarrow$ & $3.78(3.27,4.37)$ & 16.55 \\
\hline Melat et.al (2011) & & $1.73(1.63,1.83)$ & 16.84 \\
\hline Segni et.al (2018) & & $2.56(2.34,2.80)$ & 16.76 \\
\hline Sofonyas A et.al (2018) & $\rightarrow$ & $3.58(3.20,4.00)$ & 16.69 \\
\hline Overall $(\mathrm{l}$-squared $=99.0 \%, \mathrm{p}=0.000)$ & & $2.25(1.49,3.39)$ & 100.00 \\
\hline NOTE: Weights are from random effects analysis & & & \\
\hline $\begin{array}{l}1 \\
1\end{array}$ & & & \\
\hline
\end{tabular}

\section{Figure 6}


Forest plot showing association of Social Support with self-care practice with $95 \%$ Cls among DM patients in Ethiopia, 2019.

\begin{tabular}{|c|c|c|c|}
\hline Study & & & $\%$ \\
\hline ID & & ES $(95 \% \mathrm{Cl})$ & Weight \\
\hline Dedefo et al (2016) & & $1.86(1.23,2.83)$ & 16.04 \\
\hline Getie et. al (2018) & $\longrightarrow$ & $5.28(4.43,6.28)$ & 17.08 \\
\hline Kassahun T et.al (2014) & & $0.61(0.45,0.82)$ & 16.63 \\
\hline Segni et.al (2018) & & $3.17(2.70,3.74)$ & 17.11 \\
\hline Sofonyas A et.al (2018) & & $10.12(6.93,14.78)$ & 16.26 \\
\hline Teklewoini et.al (2017) & & $4.09(3.23,5.18)$ & 16.89 \\
\hline Overall (I-squared $=97.4 \%, p=0.000$ ) & & $3.04(1.64,5.65)$ & 100.00 \\
\hline NOTE: Weights are from random effects & & & \\
\hline 1 & & & \\
\hline
\end{tabular}

\section{Figure 7}

Forest plot showing of the association of having Glucometer at home and diabetic's self-care practice among DM patients in Ethiopia, 2019. 


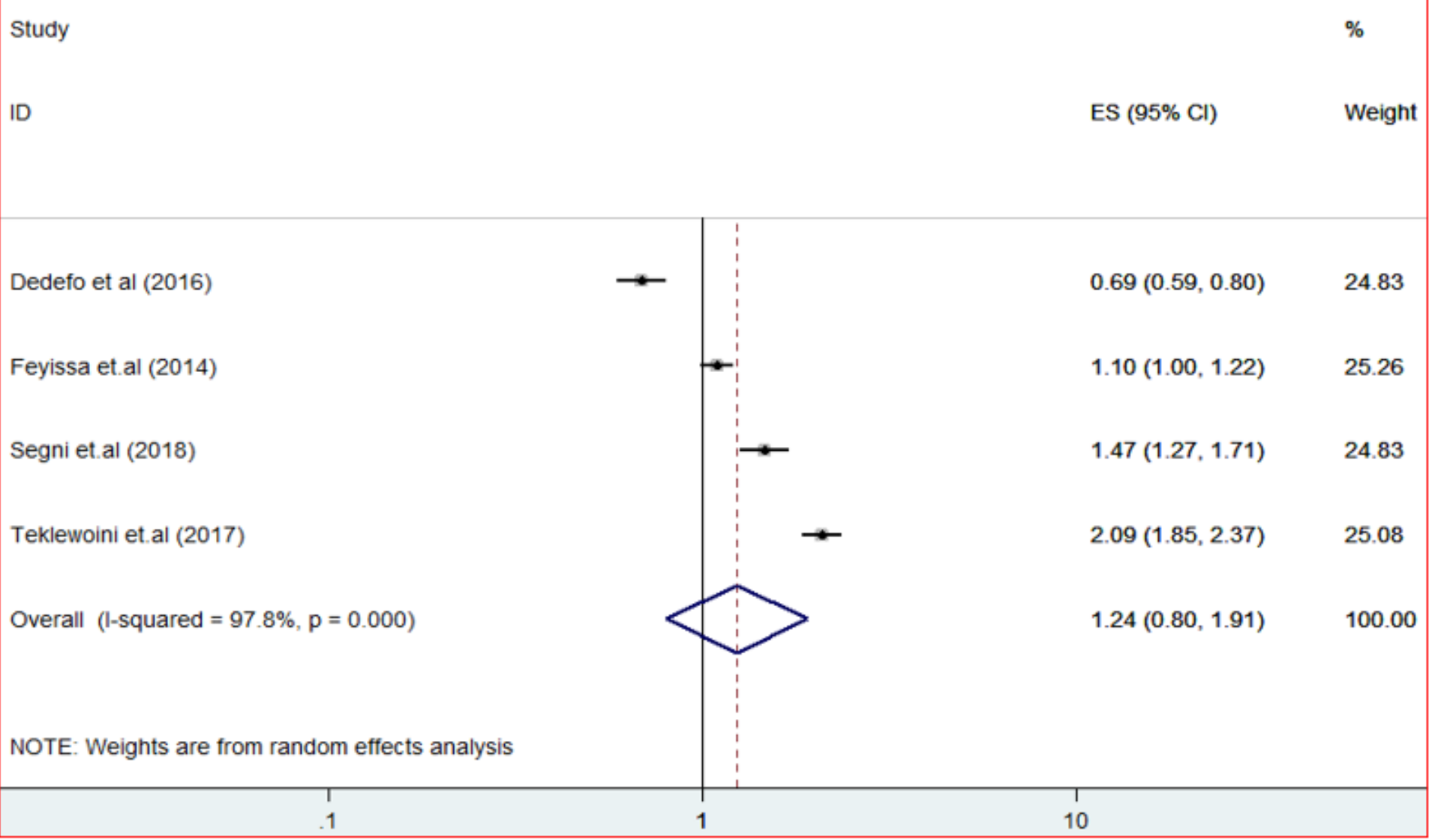

\section{Figure 8}

Forest plot showing of presence of co-morbidity on diabetic's self-care practice among DM patients in Ethiopia, 2019. 


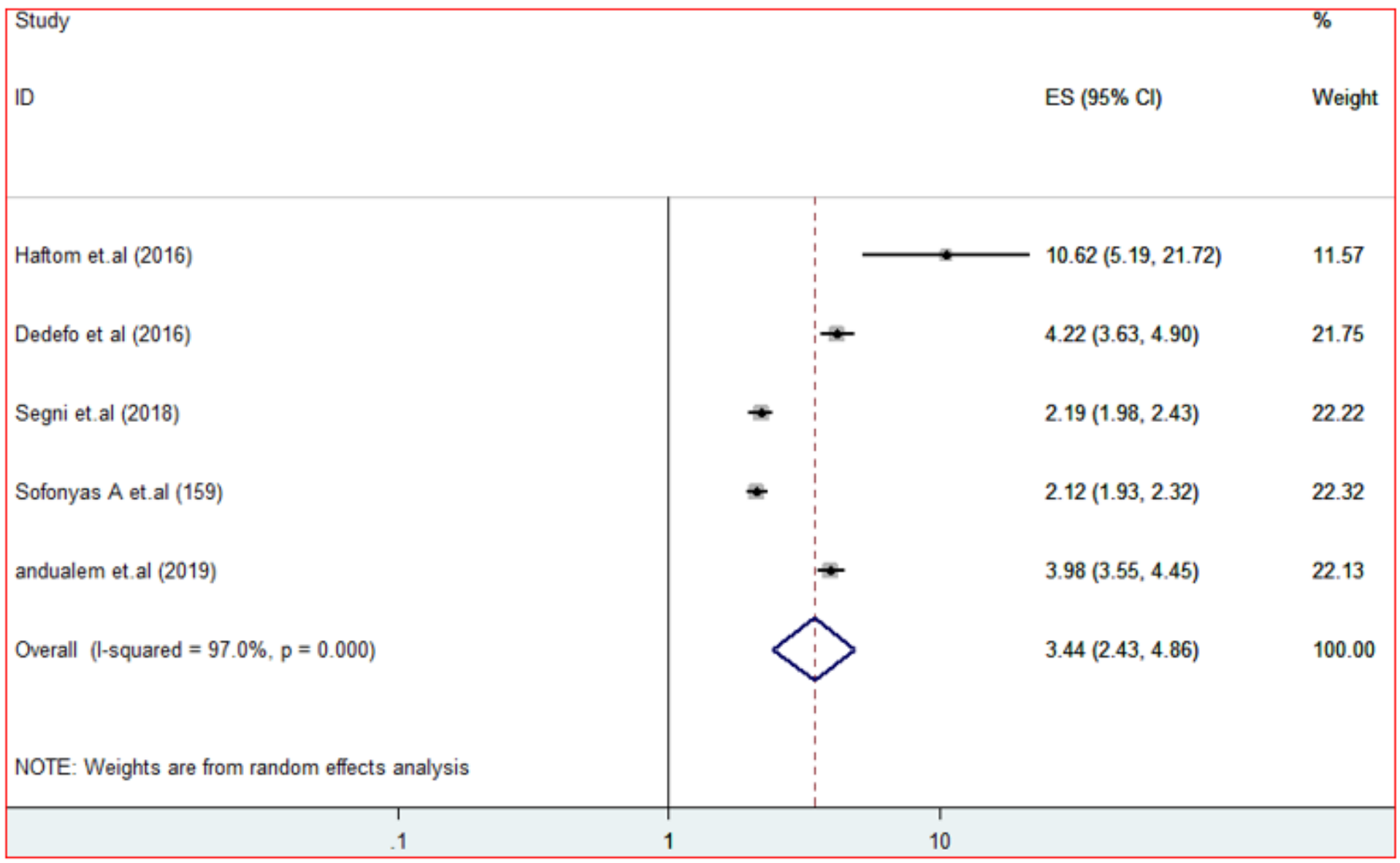

\section{Figure 9}

Forest plot showing relationship between residence and diabetic's self-care practice among Adult DM patients in Ethiopia with 95\% Cls, 2019.

\section{Supplementary Files}

This is a list of supplementary files associated with this preprint. Click to download.

- AdditionalFile2Prismacheckilist.docx 